\title{
Regionalização em saúde em Minas Gerais: uma análise da percepção dos representantes de Comissóes Intergestores Regionais
}

\section{I ${ }^{1}$ Vinícius Oliveira de Moura Pereira, ${ }^{2}$ Helena Eri Shimizu, \\ ${ }^{3}$ Maíra Catharina Ramos, ${ }^{4}$ Christopher William Fagg I}

Resumo: Este estudo tem como objetivo analisar a percepção de representantes de Comissôes Intergestores Regionais (CIRs) sobre o processo de regionalização em saúde no Estado de Minas Gerais. Foram realizadas entrevistas com representantes de dez regióes de saúde do estado. Os dados, analisados por meio do software IRAMUTEQ, geraram um dendograma com dois eixos temáticos. O primeiro eixo, denominado "O papel das CIRs e dos principais atores no processo de governança regional”, subdividiu-se nas classes 4 , 3 e 2, que abordaram, respectivamente, o protagonismo dos apoiadores do Conselho de Secretarias Municipais de Saúde (COSEMS) nas CIRs; a CIR como espaço de pactuação das açôes regionais; atores envolvidos na governança da região de saúde. O segundo, denominado "Organização da assistência nas redes de atenção”, subdividiu-se nas classes 5, 1 e 6, que descreveram, respectivamente, vazios assistenciais nas regióes de saúde; fragilidades e potencialidades do processo de regionalização; dificuldades de provisão de serviços de média e alta complexidade. A regionalização em saúde em Minas Gerais, apesar de estratégias bem-sucedidas, apresenta grandes desafios. O financiamento insuficiente do SUS, em um cenário de disputas políticas, e fragmentação de recursos prejudica a provisão da atenção nas regióes de saúde. Trata-se, portanto, de um processo em construção.

> Palavras-chave: regionalização; Sistema Único de Saúde; governança; descentralização; serviços de saúde.

\author{
1 Universidade de Brasília. \\ Brasília-DF, Brasil (viniciusomp@ \\ yahoo.com.br). \\ ORCID: 0000-0002-0529-7603 \\ ${ }^{2}$ Universidade de Brasília, Saúde \\ Coletiva. Brasília-DF, Brasil \\ (shimizu@unb.br). \\ ORCID: 0000-0001-5612-5695 \\ ${ }^{3}$ Hospital Israelita Albert \\ Einstein. São Paulo-SP, Brasil \\ (mairacramos@gmail.com). \\ ORCID: 0000-0003-3829-975X \\ ${ }_{4}^{4}$ Universidade de Brasília, \\ Farmácia. Brasília-DF, Brasil \\ (fagg@unb.br). \\ ORCID: 0000-0001-6072-7832
}

Recebido em: 04/10/2019 Aprovado em: 16/12/2019 Revisado em: 31/01/2020 


\section{Introdução}

A regionalização da saúde inscreve-se no contexto de descentralização política e administrativa das açóes e serviços. Esse processo é fruto das políticas de redemocratização implementadas no Brasil desde a Constituição Federal de 1988. Desde então, o arcabouço normativo do Sistema Único de Saúde (SUS) avançou no sentido da superação do centralismo autoritário do governo federal, com a consolidação de diretrizes para os processos de descentralização e regionalização (REIS et al., 2017). Nesse contexto, é importante destacar as Leis Orgânicas do SUS (8.080 e 8.142, de 1990), as Normas Operacionais Básicas (NOB 01/91, 01/92, 01/93 e 01/96), as Normas de Organização da Assistência à Saúde (NOAS 2001 e NOAS 2002) e o Pacto pela Saúde (2006) como marcos legislativos que vêm dando concretude à implantação do SUS. A Portaria Ministerial no 4.279/10 e o Decreto no 7.508/11 contribuíram para o modelo de redes de atenção e para que gestores municipais assumam gradativamente novas responsabilidades nas regiôes de saúde (MOREIRA; FERRÉ; ANDRADE, 2017; REIS et al., 2017).

Na América Latina, a descentralização e a regionalização vêm sendo implementadas desde a década de 1970, porém com maior destaque para a descentralização, o que contribuiu para a fragmentação dos sistemas de saúde dessa região (LIMA; VIANA et al., 2012). A análise da literatura nacional mostra a regionalização como uma das soluçôes para a redução das grandes desigualdades internas do país (RIBEIRO et al., 2017). Do ponto de vista conceitual, a regionalização é compreendida como um processo técnico-político condicionado pela capacidade de oferta e financiamento da atenção à saúde e também pela distribuição de poder e pelas relaçóes estabelecidas entre governos, organizações públicas, privadas e cidadãos, em diferentes espaços geográficos (LIMA; QUEIROZ et al., 2012).

Nessa lógica, o Decreto no 7.508 de 28 de junho de 2011 define Região de Saúde como:

Espaço geográfico contínuo constituído por agrupamentos de municípios limítrofes, delimitados a partir de identidades culturais, econômicas e sociais, de redes de comunicação e infraestrutura de transportes compartilhados, com a finalidade de integrar a organização, o planejamento e a execução de açôes e serviços de saúde. (BRASIL, 2011, p. 1).

A conformação de regiōes e redes de saúde é estratégia da política nacional para lidar com a dimensão territorial da universalização da saúde e induzir mudanças na 
política, no planejamento e na gestão do SUS, com o objetivo de viabilizar uma ação mais eficaz do Estado na garantia do direito à saúde (ALBUQUERQUE et al., 2015).

O avanço da regionalização da saúde no Brasil vem se dando de forma desigual, por depender de múltiplos fatores, dentre eles: a forma de condução do processo de regionalização pelas Secretarias Estaduais de Saúde, especialmente em relação ao fortalecimento ou não das instâncias regionais de discussão; a existência de uma cultura de negociação intergovernamental, a exemplo dos consórcios intermunicipais enquanto modelos importantes para superar lacunas na assistência à saúde da população (NEVES; RIBEIRO, 2006); a experiência acumulada em planejamento governamental; a existência de lógicas territoriais de integração de serviços que extrapolam as redes urbanas; bem como as diferenças relacionadas ao desenvolvimento socioeconômico e à oferta de serviços de saúde nos distintos territórios brasileiros, condicionantes estruturais da regionalização (VIANA et al., 2015; LIMA; QUEIROZ et al., 2012).

As regiōes de saúde, espaços estruturados por meio de redes assistenciais de caráter técnico e político, abrigam diversidades e desigualdades socioespaciais e envolvem a negociação entre agentes e instituições, com demandas e interesses divergentes e conflituosos (ALBUQUERQUE et al., 2015). O Estado de Minas Gerais, a exemplo da realidade brasileira, apresenta distintos perfis de regiôes de saúde, tanto no que diz respeito a aspectos socioeconômicos quanto em relação à oferta de serviços de saúde (ALVES et al., 2017; MOREIRA; FERRÉ; ANDRADE, 2017). Possui extensão territorial de $586.520,732 \mathrm{~km} 2$, população estimada de 21.119.536 habitantes em 2017, e é composto por 853 municípios (IBGE, 2018). É organizado em 77 Regiōes de Saúde, que formam 13 Regióes Ampliadas de Saúde, com diferentes características culturais, diferenças de desenvolvimento econômico e social e distintos perfis de morbimortalidade e desigualdade quanto à distribuição geográfica dos serviços de saúde (MALACHIAS; LELES; PINTO, 2010). Essa realidade regional impóe grandes desafios para a organização das redes de atenção à saúde e operacionalização da Portaria no 4.279/10 e do Decreto no 7.508/11 (MOREIRA; FERRÉ; ANDRADE, 2017).

Nesse sentido, estudos sobre a regionalização em saúde nos diferentes territórios brasileiros são relevantes para se identificar os avanços e desafios desse processo e disponibilizar subsídios para o delineamento e a adequação de políticas públicas que busquem aprimorá-lo. É relevante analisar os fatores que possam favorecer ou 
dificultar o processo de regionalização, de forma a compreender potenciais entraves à ampliação do acesso à saúde. (ALVES et al., 2017; LIMA; VIANA et al., 2012; MALACHIAS; LELES; PINTO, 2010).

O objetivo deste estudo foi analisar a percepção de representantes de Comissôes Intergestores Regionais (CIR) sobre o processo de regionalizaçâo em saúde no Estado de Minas Gerais, bem como as suas fragilidades e potencialidades.

\section{Métodos}

\section{Delineamento, população de estudo e aspectos éticos}

Este trabalho é parte integrante da pesquisa Avaliação do Processo de Regionalização em Saúde no Brasil, financiada pelo Conselho Nacional de Desenvolvimento Científico e Tecnológico (CNPq) e apoiada pelo Ministério da Saúde. Trata-se de estudo qualitativo, do tipo descritivo-exploratório, realizado em dez regiôes de saúde do estado de Minas Gerais, selecionadas por meio de amostra de conveniência a partir de extratos populacionais. As regiôes foram ordenadas de acordo com o tamanho da população, de forma decrescente. Foram selecionadas as regiōes de saúde mais populosas e, consequentemente, as localizadas no primeiro ao nono decil da ordenação, com o objetivo de obter regióes de diferentes tamanhos populacionais. Dentre as regiões selecionadas, uma (10\%) apresentava população acima de 500.000 habitantes; sete (70\%), população entre 100.000 e 500.000 habitantes; e duas (20\%), população inferior a 100.000 habitantes.

Para cada regiáo de saúde selecionada foi entrevistado um representante da respectiva CIR, que se disponibilizou a participar da pesquisa. Foram definidos como critérios de inclusão: regiōes de saúde criadas há mais de um ano; representantes que haviam participado de pelo menos três reunióes da CIR. Critério de exclusão: foram descartados os representantes das CIRs que apresentavam menos de três meses de experiência na função.

Em relação às características gerais dos entrevistados, a maior parte (60\%) era do sexo feminino, possuía em média 10,7 anos de experiência em gestão no SUS e 6,9 anos na função de integrante da CIR. Quanto à formação profissional, 50\% possuíam curso superior em Enfermagem; 20\%, em Administração de Empresas; 10\%, em Fisioterapia; 10\%, em Farmácia-Bioquímica; e 10\%, em Direito. No tocante ao cargo ocupado, havia cinco secretários municipais de Saúde, quatro 
secretários executivos de CIR e um apoiador do Conselho de Secretarias Municipais de Saúde de Minas Gerais (COSEMS-MG). Eles eram representantes das CIRs das seguintes regiôes de saúde: São João Del Rey; Sete Lagoas; Pirapora; Minas Novas/Turmalina/Capelinha; Manga; Leopoldina/Cataguases; Itaobim; Itajubá; Belo Horizonte/Nova Lima/Caeté; Ubá.

O projeto de pesquisa foi aprovado por Comitê de Ética em Pesquisa (parecer 1.074.909), e todos os participantes assinaram o Termo de Consentimento Livre e Esclarecido.

\section{Coleta de dados e roteiro de entrevista}

Utilizou-se um roteiro de entrevista semiestruturado que abordou os seguintes domínios: organização e funcionamento da CIR; planejamento da Região de Saúde; organização do fluxo e regulação assistencial; financiamento dos serviços regionais; comunicação da CIR; dimensão cultural e relações na região de saúde; e governança da CIR. Ressalte-se que os entrevistados puderam falar livremente sobre esses tópicos.

As entrevistas foram realizadas por três pesquisadores treinados e com domínio no instrumento de coleta, tiveram duração de aproximadamente 40 minutos e ocorreram no período de novembro de 2016 a outubro de 2017.

\section{Análise dos dados}

Utilizou-se a análise de conteúdo, mais especificamente a análise de coocorrência, com o auxílio do software IRAMUTEQ (Interface de $R$ pour les Analyses Multidimensionnelles de Textes et de Questionnaires), versão 0.7 alpha 2, que permite realizar análises estatísticas de corpus textuais, como a lexicografia básica que faz o cálculo de frequência de palavras, até análises multivariadas, como Classificação Hierárquica Descendente (CHD) (CAMARGO; JUSTO, 2013; SHIMIZU et al., 2017).

Optou-se por utilizar a CHD das entrevistas semiestruturadas, na qual os segmentos de texto são classificados em função dos seus respectivos vocabulários, e agrupados em classes que apresentam vocabulário semelhante entre si. O software organiza a análise dos dados em um dendograma da $\mathrm{CHD}$, que ilustra as relaçôes entre as classes, executa testes, como o chi2 (X2 de associação da palavra com a classe) e fornece resultados que permitem a descrição de cada uma das classes, 
principalmente pelo seu vocabulário característico e por suas variáveis (CAMARGO; JUSTO, 2013; SHIMIZU et al., 2017).

As classes geradas a partir da CHD representam o contexto de sentido das palavras e colocam em destaque mundos lexicais de palavras-plenas que têm por referência um mesmo núcleo de sentido. Os eixos temáticos, com as respectivas classes, demonstram as representaçóes compartilhadas pelos sujeitos acerca dos aspectos ou domínios relacionados à regionalização em saúde no Estado de Minas Gerais, que demandaram análise hermenêutica para se compreender o texto e o contexto de produção de significados (SHIMIZU et al., 2017).

Ademais, foi realizada a análise de similitude, que possibilita identificar as coocorrências entre as palavras, e seu resultado traz indicaçóes da conexidade entre as palavras, o que auxilia na identificação da estrutura do conteúdo de um corpus textual (CAMARGO; JUSTO, 2013). Para o processamento da análise de similitude foram desconsiderados os advérbios do corpus e selecionadas as 50 palavras mais frequentes.

\section{Resultados}

O software identificou 669 segmentos de texto. A quantidade total de palavras utilizadas na análise foi de 23.168 e, quando desconsideradas as repetições, 2.900 palavras ou formas. Essas formas foram levadas às suas raízes, o que resultou num total de 1.890 lemas ou palavras da mesma raiz lexical. Destaca-se que 557 dos 669 segmentos de texto $(83,26 \%)$ foram aproveitados para esta análise.

Das análises emergiram dois eixos temáticos, que se subdividiram e deram origem a seis classes de segmentos de texto (figura 1). O primeiro eixo, denominado "O papel das CIRs e dos principais atores no processo de governança regional”, subdivide-se nas classes 4, 3 e 2, que abordaram, respectivamente, "O protagonismo dos apoiadores do Conselho de Secretarias Municipais de Saúde (COSEMS) nas CIRs"; "A CIR como espaço de pactuação das açóes regionais"; e "Os atores envolvidos na governança da região de saúde". O segundo eixo foi denominado "Organização da assistência nas redes de atenção" e subdivide-se nas classes 5, 1 e 6, que descreveram, respectivamente, "Vazios assistenciais nas regiôes de saúde"; "Fragilidades e potencialidades do processo de regionalização" e "Dificuldades de provisão de serviços de média e alta complexidade". O quadro 1 apresenta a síntese dos principais resultados obtidos por meio das classes de palavras organizadas pelo dendograma. 


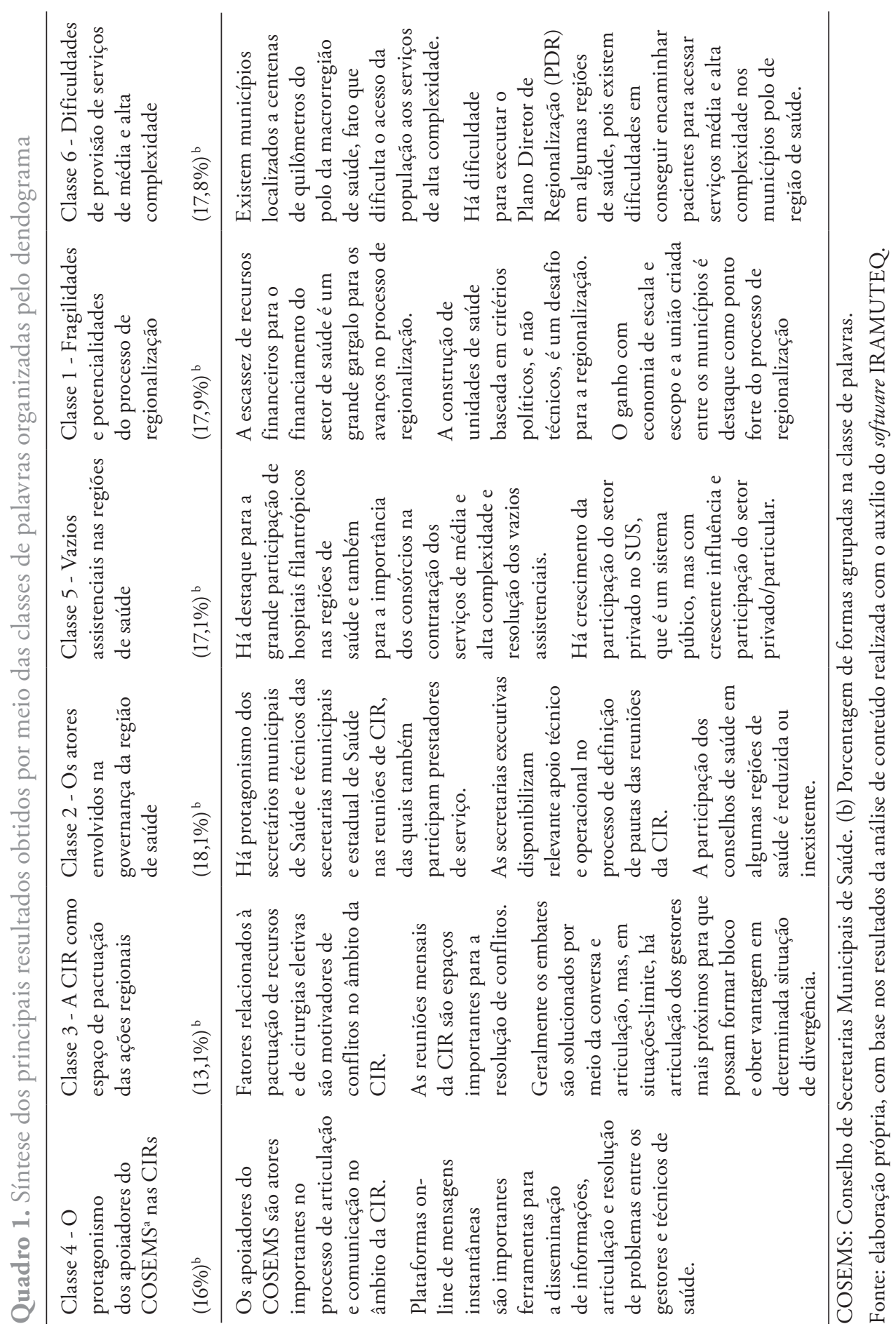


Figura 1. Eixos temáticos e classes de segmentos de texto

\begin{tabular}{|c|c|c|c|c|c|}
\hline \multicolumn{3}{|c|}{$\begin{array}{l}\text { Eixo } 1 \text { - O papel das CIRs e dos principais atores no } \\
\text { processo de governança regional }\end{array}$} & \multicolumn{3}{|c|}{ Eixo 2 - Organização da assistência nas redes de atenção } \\
\hline $\begin{array}{l}\text { Classe } 4 \text { - O pro- } \\
\text { tagonismo dos } \\
\text { apoiadores do } \\
\text { COSEMS nas CIRs }\end{array}$ & $\begin{array}{c}\text { Classe } 3 \text { - A CIR } \\
\text { como espaço de } \\
\text { pactuação das } \\
\text { ações regionais }\end{array}$ & $\begin{array}{l}\text { Classe } 2 \text { - Os } \\
\text { atores envolvidos } \\
\text { na governança da } \\
\text { região de saúde }\end{array}$ & $\begin{array}{l}\text { Classe } 5 \text { - Vazios } \\
\text { assistenciais nas } \\
\text { regiões de saúde }\end{array}$ & $\begin{array}{l}\text { Classe } 1 \text { - Fragili- } \\
\text { dades e potenciali- } \\
\text { dades do processo } \\
\text { de regionalização }\end{array}$ & $\begin{array}{l}\text { Classe } 6 \text { - Dificul- } \\
\text { dades de provisão de } \\
\text { serviços de média e } \\
\text { alta complexidade }\end{array}$ \\
\hline $16 \%$ & $13,1 \%$ & $18,1 \%$ & $17,1 \%$ & $17,9 \%$ & $17,8 \%$ \\
\hline $\begin{array}{l}\text { apoiador } \\
\text { informação } \\
\text { WhatsApp } \\
\text { inclusive } \\
\text { prefeito } \\
\text { logístico } \\
\text { fórum } \\
\text { rápido } \\
\text { portaria } \\
\text { sair } \\
\text { perguntar } \\
\text { secretário } \\
\text { curso } \\
\text { COSEMS } \\
\text { comunicação } \\
\text { gerência } \\
\text { grupo } \\
\text { junto } \\
\text { presença } \\
\text { início } \\
\text { hoje } \\
\text { ler } \\
\text { de repente gestor } \\
\text { gestor } \\
\text { disponibilizar } \\
\text { acontecer }\end{array}$ & $\begin{array}{l}\text { conflito } \\
\text { reunião } \\
\text { nunca } \\
\text { ano } \\
\text { mês } \\
\text { até } \\
\text { reunir } \\
\text { mensal } \\
\text { resolver } \\
\text { trazer } \\
\text { ClB } \\
\text { participar } \\
\text { resolvido } \\
\text { discutir } \\
\text { geralmente } \\
\text { problema } \\
\text { depois } \\
\text { gestor } \\
\text { tentar } \\
\text { pactuações } \\
\text { ocorrer } \\
\text { conselheiro } \\
\text { compor } \\
\text { discussão } \\
\text { assunto } \\
\text { menos }\end{array}$ & $\begin{array}{l}\text { municipal } \\
\text { pauta } \\
\text { secretaria } \\
\text { membro } \\
\text { coordenador } \\
\text { técnico } \\
\text { comissão } \\
\text { executivo } \\
\text { núcleo } \\
\text { saúde } \\
\text { secretária } \\
\text { pedir } \\
\text { CIRs } \\
\text { temática } \\
\text { técnica } \\
\text { direito } \\
\text { câmara } \\
\text { consultor } \\
\text { convidar } \\
\text { conselho } \\
\text { coordenação } \\
\text { estadual } \\
\text { representante } \\
\text { solicitar } \\
\text { voz } \\
\text { formado }\end{array}$ & $\begin{array}{l}\text { hospital } \\
\text { vazio assistencial } \\
\text { SUS } \\
\text { filantrópico } \\
\text { contratar } \\
\text { credenciar } \\
\text { fluxo } \\
\text { utilizar } \\
\text { ortopedia } \\
\text { acabar } \\
\text { responsabilidade } \\
\text { talvez } \\
\text { particular } \\
\text { interface } \\
\text { entrada } \\
\text { público } \\
\text { maior } \\
\text { privado } \\
\text { por cento } \\
\text { porta } \\
\text { fácil } \\
\text { restante } \\
\text { pediatria } \\
\text { credenciamento } \\
\text { meta } \\
\text { judicialização }\end{array}$ & $\begin{array}{l}\text { achar } \\
\text { regionalização } \\
\text { não } \\
\text { funcionar } \\
\text { conseguir } \\
\text { dentro } \\
\text { CISMA } \\
\text { convênio } \\
\text { realmente } \\
\text { ponto } \\
\text { nada } \\
\text { união } \\
\text { melhor } \\
\text { município } \\
\text { forma } \\
\text { fraco } \\
\text { questão } \\
\text { tabela } \\
\text { posse } \\
\text { SAMU } \\
\text { suporte } \\
\text { atuante } \\
\text { aí } \\
\text { bem } \\
\text { população } \\
\text { PPI }\end{array}$ & $\begin{array}{l}\text { alta complexidade } \\
\text { paciente } \\
\text { exemplo } \\
\text { média complexidade } \\
\text { Bahia } \\
\text { atender } \\
\text { oncologia } \\
\text { perto } \\
\text { Brasilia } \\
\text { divisa } \\
\text { Diamantina } \\
\text { centro } \\
\text { cirurgia } \\
\text { complexidade } \\
\text { polo } \\
\text { monte } \\
\text { tripolar } \\
\text { capela } \\
\text { Barbacena } \\
\text { médio } \\
\text { mina } \\
\text { programa } \\
\text { São João Del Rey } \\
\text { leito } \\
\text { quilômetro } \\
\text { sede }\end{array}$ \\
\hline
\end{tabular}

Fonte: os autores

No tocante ao primeiro eixo, que trata da importância da CIR e dos principais atores no processo de governança regional, destaca-se a classe 4, que aborda o protagonismo dos apoiadores do Conselho de Secretarias Municipais de Saúde de Minas Gerais (COSEMS-MG) nas CIRs e agrupa 16\% das formas.

Os apoiadores do COSEMS foram destacados como atores importantes no processo de articulação e comunicação no âmbito da CIR. Foi considerado que eles disponibilizam apoio técnico e logístico para o funcionamento da CIR, participam de processos de capacitação, atuam na resolução de problemas e como mediadores na comunicação entre as gestôes do estado e municípios.

[...] hoje tem uma ligação muito maior com o COSEMS, através do apoiador. Se eu tenho um problema com o município, não vou diretamente ao município. Eu peço à apoiadora para que ela, por dentro do COSEMS, resolva para nós, e vice-versa. Então nós temos essa ligação entre estado e município através do COSEMS. (Entrevistado 4) 
Ainda em relação à comunicação, plataformas on-line de mensagens instantâneas foram percebidas como importantes ferramentas para a disseminação de informaçôes, articulação e resolução de problemas entre os gestores e técnicos de saúde de forma mais rápida. $\mathrm{O}$ aplicativo WhatsApp, bem como fóruns de comunicação on-line, foi destacado em diversas entrevistas como importante instrumento utilizado nesse processo.

É uma ferramenta de comunicação rápida. A informação é em tempo real. Saiu a portaria hoje, hoje mesmo está no fórum, quem quiser abrir, acessar, incluir observaçôes, contribuiçôes, chamar a atenção do secretário, cobrar sobre não atendimento do seu munícipe, que podem ser os mesmos problemas de outros. (Entrevistado 3).

Hoje a informação está aí, a todo momento, e acontece muito rápido. Então eu acho que, com o advento do WhatsApp, dos e-mails, a questão da prioridade das informaçóes através dessas redes tem agilizado muito a informação. (Entrevistado 10).

A classe 3 aborda a CIR como espaço de pactuação das ações regionais e agrupa $13,1 \%$ das formas.

Foi destacado que as reuniôes de CIR, que geralmente ocorrem com periodicidade mensal, são espaços importantes para a resoluçáo de conflitos. Fatores relacionados à pactuação de recursos e de cirurgias eletivas são motivadores de conflitos. Foi salientado que geralmente os embates são solucionados por meio da conversa e articulação dos atores da CIR, pois existe uma relação de parceria entre eles.

[...] já tivemos algumas reuniôes extraordinárias para resolver conflitos, principalmente quando se fala em pactuaçóes de recursos e cirurgias eletivas. (Entrevistado 3).

Tivemos esse ano um impasse que não foi resolvido em uma só reunião, (nos) reunimos até que se esgotassem as discussóes e se chegasse a um consenso. (Entrevistado 5).

Normalmente, o conflito que existe nós tentamos resolver na consciência, na parceria. (Entrevistado 7).

Entretanto, em situaçôes-limite, há articulação dos gestores mais próximos para que possam formar bloco e obter vantagem em determinada situação de divergência.

Geralmente a gente tem os grupos de afinidade aí já é malandragem mesmo. (Se) Tem conflito e eu vou ser prejudicado, me comunico por WhatsApp com os gestores que estão mais próximos, juntamos a corrente para ir contra ou a favor [...]. (Entrevistado 1).

A classe 2 descreve os atores envolvidos na governança das regióes de saúde, bem como aspectos operacionais de funcionamento, e agrupa $18,1 \%$ das formas.

Em relação à participação nas reuniôes da CIR foi destacado o protagonismo dos gestores e técnicos das secretarias municipais e estadual de Saúde. Também 
foi ressaltada a participação dos prestadores de serviço, incluindo os representantes de consórcios de saúde.

Os participantes são os secretários de Saúde, os coordenadores referências técnicas do estado também participam, e os visitantes, que são convidados de acordo com o tema [...]. (Entrevistado 4).

[...] quando convidados, os prestadores também participam. Se dentro da comissão temática tiver uma pauta que é questionada alguma ação do prestador, convidamos ele. (Entrevistado 8).

As propostas de pautas das reunióes, principalmente as que envolvem pactuaçóes, são previamente encaminhadas às comissóes temáticas da CIR, compostas por representantes municipais e estaduais, nas quais são feitas as avaliaçôes e ajustes, e então definida a pauta. Nesse processo, foi salientado também o relevante apoio técnico e operacional disponibilizado pelas secretarias executivas das CIRs, que contribuem para que as pautas propostas sejam discutidas e articuladas entre os gestores.

Depois da comissão temática, fazemos a CIR na semana seguinte [...]. Passou pela discussão (na comissão), verificou o que é pauta, e a CIR é convocada. (Entrevistado 8).

E sempre há um consenso entre COSEMS e o estado, o que vai entrar em pauta. Quando há consenso entra, quando não há, há discussão interna. Então sempre tem uma secretária executiva que representa a regiáo e que discute com a gente antecipadamente a pauta. (Entrevistado 9).

Em relação à participação do controle social, foi informado que em algumas CIRs os Conselhos de Saúde são convidados para as reuniōes e têm participação ativa. Entretanto, em outras regióes os conselhos estão ausentes e a participação nas reunióes é mínima.

No que concerne ao segundo eixo temático, que evidencia os desafios relacionados à organização da assistência nas redes de atenção, a classe 5 descreve os vazios assistenciais nas regióes de saúde e agrupa $17,1 \%$ das formas.

Foi destacada a grande participação de hospitais filantrópicos nas regióes de saúde e também a importância dos consórcios para a contratação dos serviços de média e alta complexidade. Os consórcios foram descritos como bem organizados e importantes para a resolução dos vazios assistenciais. Nesse aspecto, alguns entrevistados destacaram o crescimento da participação do setor privado no SUS, que é um sistema público, mas com crescente influência e participação do setor privado/particular. 
Então essas tomografias são feitas nesses hospitais filantrópicos, e o que passa disso é feito via consórcio, que compra essa cota por licitaçáo, pregáo para repassar pra gente de acordo com a nossa demanda. (Entrevistado 6).

[...] estamos lutando muito para fortalecer o consórcio. Para não ficar muito na mão do prestador privado, que muitas das vezes não vai fazer um preço que o município possa pagar. [...] (o consórcio) tem que seguir toda uma regra para contrataçáo de serviços que o prestador particular náo tem [...] Mas hoje a realidade dos prestadores privados e os filantrópicos é muito forte na nossa região. (Entrevistado 10).

[...] hoje, nós estamos falando de SUS, mas terceirizando tudo. Estamos particularizando tudo de novo. Porque nos hospitais agora realmente é difícil você manter um serviço com o valor de procedimento que o SUS oferece. O que você faz? Você vai terceirizar. E aí os particulares estáo tomando conta. [...] Vai ter um dia que você não vai aguentar pagar. $\mathrm{Na}$ regionalização, tem que ter essa questão de valorizar e estruturar o SUS realmente. E não particularizar, que é o que está acontecendo. (Entrevistado 4).

A falta de especialidades médicas nas regióes de saúde, principalmente ortopedia e pediatria, mas também cardiologia, oftalmologia, oncologia e neurologia, foi salientada como importante vazio assistencial. Foi informado também que alguns municípios utilizam o sistema SUS Fácil e outros municípios o Sistema Nacional de Regulação (SISREG), para organizar e regular o fluxo assistencial nas regiốes de saúde.

A classe 1 aborda fragilidades e potencialidades do processo de regionalização em saúde e agrupa 17,9\% das formas. Foi destacado que um grande gargalo para os avanços no processo de regionalização é a escassez de recursos para o financiamento do setor de saúde. Esse problema, que é um ponto fraco da proposta de regionalização, contribui para que os municípios apresentem dificuldades para compartilhar serviços e recursos, que são reduzidos.

Os municípios sozinhos não conseguem disponibilizar atenção integral à população. $\mathrm{O}$ acesso às atençôes secundária e terciária não é viabilizado de forma adequada. Nesse sentido, a regulação dos serviços na região de saúde, bem como a existência de consórcios, e dos contratos/convênios firmados por meio desses contratos contribui para melhorar a assistência disponibilizada. De forma geral, foi ressaltado que a estratégia dos consórcios funciona bem nas regiōes de saúde.

Se o estado e o ministério não oferecerem, eles (municípios) sozinhos não conseguem oferecer nada, porque não têm condição financeira para isso, a não ser o consórcio, que também tem seus grandes gargalos. (Entrevistado 4).

A construção de unidades de saúde baseada em critérios políticos, e não técnicos, foi um ponto destacado pelos entrevistados como desafio para a regionalização. Como 
exemplo, foi informado que há grande interesse de municípios em construir hospitais locais, que em muitas situaçóes não são resolutivos, apresentam custos elevado e não estão alinhados com a organização da rede de atenção na região de saúde.

[...] eles (municípios) querem um serviço de metrópole, dentro de uma cidade de oito mil habitantes [...]. Eu quero um elefante branco aqui, porque o político tal libera as emendas parlamentares, que faz construir um hospital numa cidade de três mil habitantes. E aí o que eu acho primeiro é essa consciência de não interferir de forma política em decisóes técnicas, que é o difícil. (Entrevistado 4).

Também foi destacado, como ponto forte do processo de regionalização, o ganho com economia de escala e escopo e a união criada entre os municípios.

O ponto forte [...] foi a questáo de economia de escala e escopo [...] todos os municípios queriam ter um hospitalzinho que não era resolutivo e tinha um custo muito grande, e até mesmo das tecnologias para exames mais complexos. (Entrevistado 2).

Eu acho que o que tem funcionado mais é a uniáo dos municípios, dos gestores. De estar detectando as falhas de referência e contrarreferência [...]. (Entrevistado 1).

A classe 6 descreve dificuldades de provisão de serviços de média e alta complexidade e agrupa $17,8 \%$ das formas.

Foi destacado que existem municípios localizados a centenas de quilômetros do polo de macrorregiấo de saúde, fato que dificulta o acesso da população aos serviços de alta complexidade, a exemplo da oncologia e cirurgias. Os longos deslocamentos à procura de atendimento e as estradas ruins são fatores prejudiciais, que contribuem para debilitar os pacientes.

[...] o município que é mais próximo da Bahia fica a 300 quilômetros de chão da sede macro, que vai ter a alta complexidade. Isso tudo faz parte da fragilidade da regionalização nossa. Questão de distância, de estradas ruins, passar cinco horas para chegar ao atendimento de oncologia, por exemplo. (Entrevistado 3).

[...] apesar de Diamantina ser referência de polo de alta complexidade, é longe, o acesso é difícil ainda. E por ser muito longe, o paciente pode se debilitar. (Entrevistado 4).

Foi destacada também a dificuldade para executar o Plano Diretor de Regionalização (PDR) em algumas regiôes de saúde, pois na prática não é fácil conseguir encaminhar pacientes para acessar serviços de média e alta complexidade nos municípios-polo de região de saúde e região ampliada de saúde.

[...] dentro do PDR a nossa assistência toda de média complexidade e algumas de alta complexidade está em Sete Lagoas, só que eles não estão nos atendendo. E aí Belo Horizonte não nos atende porque é responsabilidade de Sete Lagoas, então nós temos enfrentado uma dificuldade muito grande, principalmente na média complexidade [...]. (Entrevistado 2). 
Ao realizar a análise de similitude (figura 2), pode-se identificar que o grande eixo organizador da regionalização em saúde é o município. Na zona periférica destacamse as regiôes de saúde e os atores envolvidos no processo de governança regional.

Figura 2. Análise de similitude

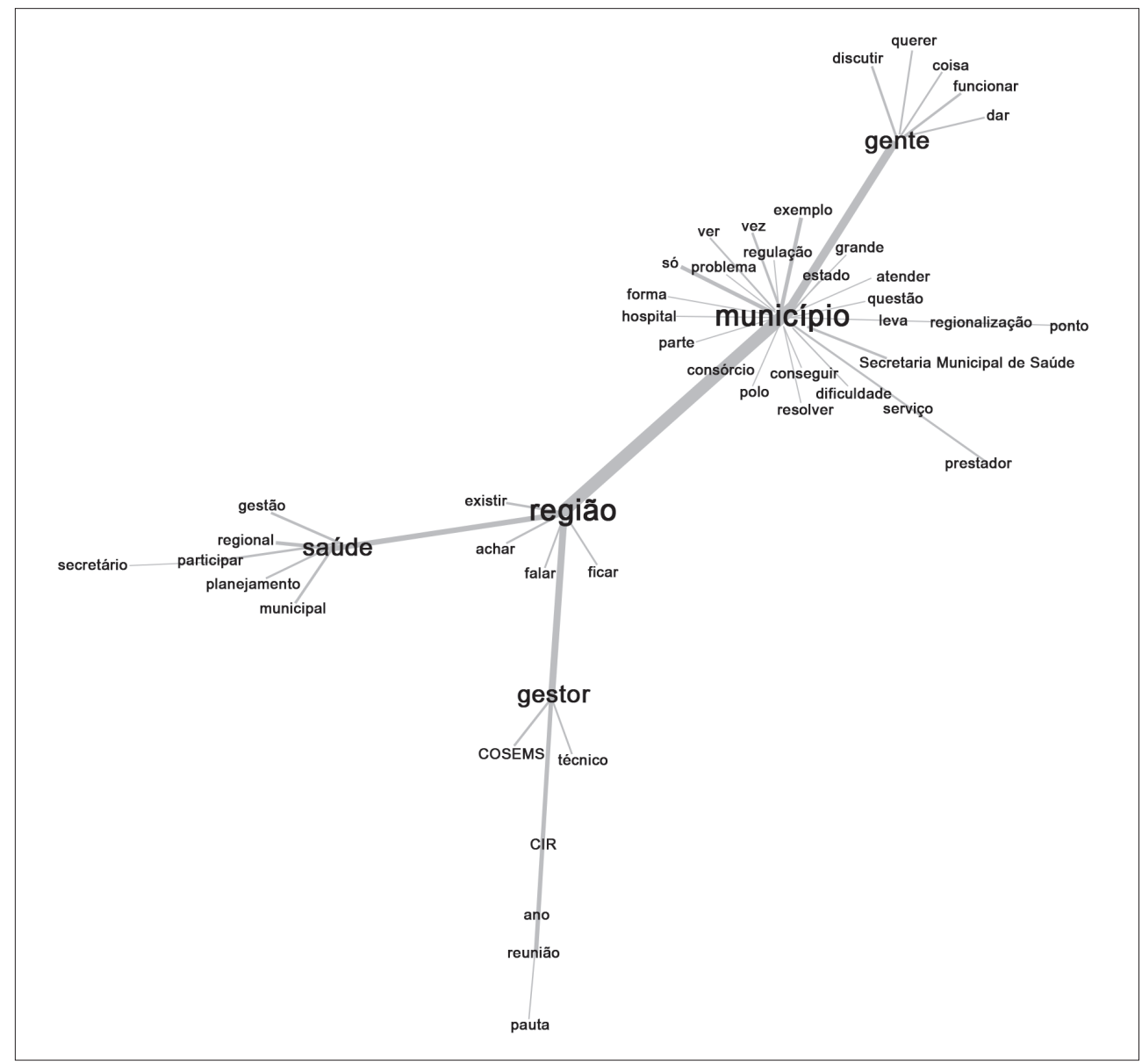

Fonte: os autores

\section{Discussão}

Verificou-se neste estudo que o Eixo 1 apresenta o protagonismo dos atores envolvidos na governança regional, a comunicação e a articulação entre esses atores, bem como o modo de operação das CIRs e a importância dessas comissôes para a comunicação e a tomada de decisão nas regiôes de saúde. 
Os apoiadores do COSEMS foram percebidos como atores importantes no processo de articulação e comunicação no âmbito da CIR (classe 4). Os apoiadores dos COSEMS são considerados figuras-chave nas regiôes de saúde e disponibilizam suporte técnico e operacional aos integrantes da CIR por meio de recursos tecnológicos e humanos (BRETAS JUNIOR et al., 2015; JUNQUEIRA; MOTTA, 2014). Ademais, eles contribuem para ampliar os canais de comunicação na CIR e a capacidade de detecção de necessidades e dificuldades nas regiôes de saúde (BRETAS JUNIOR et al., 2015; JUNQUEIRA; MOTTA, 2014). Nesse contexto, é importante destacar que Minas Gerais conta com 22 apoiadores, que têm como principal atividade o apoio técnico aos COSEMS regionais, subsidiando as açóes regionais para enfrentar os problemas decorrentes da assimetria de informação, fragmentação institucional do COSEMS e fortalecimento da capacidade técnica municipal (BRETAS JUNIOR et al., 2015).

Em relação à comunicação nas regióes de saúde, por meio do Fórum Regional, plataforma on-line de discussão desenvolvida pelo COSEMS e mediada pelos apoiadores regionais, são discutidos e contextualizados temas de interesse dos integrantes da CIR (BRETAS JUNIOR et al., 2015; JUNQUEIRA; MOTTA, 2014).

Em relação à classe 3, as CIRs foram referenciadas como espaços de pactuação, cooperação e resolução de conflitos nas regiôes de saúde. As CIRs representam fóruns potenciais de debates e construção de estratégias de governança regional (SILVEIRA FILHO et al., 2016). Nesse sentido, é válido destacar que, apesar dos grandes desafios, o Estado de Minas Gerais tem mobilizado esforços para o fortalecimento desses importantes espaços de governança e para os avanços no processo de regionalização (BRETAS JUNIOR et al., 2015; JUNQUEIRA; MOTTA, 2014).

Os conflitos relacionados ao processo de regionalização giram em torno do acesso limitado aos serviços de saúde pelos municípios, dos interesses econômicos distintos, embates políticos e competitividade entre os municípios e entre esses e o estado (SILVA; GOMES, 2013). Nesse sentido, é importante destacar que, no contexto da América Latina, os processos de descentralização e regionalização nos sistemas de saúde ocorridos desde a década de 1970 foram conduzidos com graus variados de articulaçáo, com maior destaque para a descentralização, o que contribuiu para a fragmentação dos sistemas de saúde, com comprometimento do acesso e da continuidade da atenção (LIMA; VIANA et al., 2012), fatores motivadores de embates nas regiốes de saúde. 
A Portaria no 4.279/10 e o Decreto no 7.508/11 contribuíram para o modelo de rede de atençáo nas regióes do estado e para que gestores municipais assumissem gradativamente novas responsabilidades nas regiōes de saúde, como a pactuação de indicadores, execução de recursos, contratualização de serviços e mediação de conflitos nas redes de atenção. Entretanto, ainda persistem as imposiçóes por parte do governo federal em relação ao acesso aos recursos financeiros que permitem incrementar o financiamento da média e alta complexidade hospitalar e ambulatorial. Nesse sentido, debates sobre os mecanismos de alocação de recursos devem ser expandidos (MOREIRA; FERRÉ; ANDRADE, 2017).

Em relação aos atores envolvidos na governança da regiáo de saúde (classe 2), este trabalho, em consonância com estudo realizado no Estado de Minas Gerais (BRETAS JUNIOR et al., 2015), destacou a importância da articulação do COSEMS junto aos participantes da CIR, para direcionar problemas que devem ou não ser encaminhados à pauta das reunióes da mesma. No que diz respeito à definição de pautas nas regióes de saúde, as comissóes temáticas das CIRs devem ordená-las nas reuniôes. Nesse sentido, é oportuno destacar que essas pautas devem estar em coerência com as prioridades do plano de ação construído no âmbito da região de saúde (BRETAS JUNIOR et al., 2015), o que ainda é um desafio para as comissôes temáticas, pois na prática há dificuldade para focar os esforços relativos aos temas prioritários para a região de saúde, baseados em critérios e necessidades regionais (BRETAS JUNIOR et al., 2015; REIS et al., 2017).

Além disso, foi evidenciado o protagonismo dos secretários municipais de Saúde e técnicos das secretarias municipais e estadual de Saúde nas reuniôes de CIR e na governança das regiôes de saúde. Nesse contexto, a palavra "município" e as derivadas, como "municipal" e "municipais", ganham destaque nas análises realizadas. Por meio da análise de similitude foi identificado o município como eixo organizador e palavra central da regionalização em saúde em Minas Gerais.

Em relação à Análise de Similitude, a "região" também foi palavra de destaque, mas situada na periferia em relaçáo ao município, localizado no eixo central da regionalização. Esse resultado pode estar relacionado ao complexo processo histórico de implementação da regionalização no SUS. Apesar de o arcabouço normativo recente avançar no sentido da consolidação de diretrizes para a regionalização e da superação da centralidade inicial na municipalização induzida 
pelas normas operacionais dos anos 1990, esse processo ainda está em construção (REIS et al., 2017; SHIMIZU et al., 2017).

A baixa participação do controle social em algumas regiōes de saúde é um problema a ser enfrentado. Diante do fato de não haver no SUS uma instância de controle social regional, até por não ser a regiáo de saúde um ente federado, é fundamental estabelecer mecanismos de articulação interconselhos, de forma a ampliar a participação social e a visibilidade da gestão no âmbito do sistema regional de saúde (BRETAS JUNIOR et al., 2015). É importante destacar que para os avanços no processo de regionalização é relevante o envolvimento da sociedade civil organizada nas instâncias de pactuação regional do SUS e que a legitimidade desse processo e do sistema de saúde é diretamente proporcional à capacidade de criar espaços permanentes de diálogo, com criatividade e autonomia dos envolvidos (REIS et al., 2017).

Observou-se que o Eixo 2 apresenta o tema dos vazios assistenciais, que comprometem a assistência à saúde nas redes de atenção, em especial os serviços de média e alta complexidade; as estratégias dos consórcios intermunicipais de saúde; e as potencialidades e fragilidades relacionadas ao processo de regionalização, com destaque para a escassez de recursos para financiamento do setor saúde.

Para a superação dos problemas relacionados aos vazios assistenciais nas regiôes de saúde, foi salientada a contribuição dos consórcios para o aumento da qualidade e da eficiência na oferta dos serviços de saúde (classe 5). Estudos apontam que os consórcios intermunicipais são modelos importantes para superar lacunas na assistência à saúde, que buscam a eficiência, a racionalidade na utilização de recursos escassos e a qualidade na oferta de serviços à população e atuam especialmente nas áreas de consultas médicas de especialidades, exames de média e alta complexidade e terapias diversas (NEVES; RIBEIRO, 2006).

Os consórcios intermunicipais existem antes mesmo da Constituição Federal de 1988 e proliferaram de forma mais consistente a partir da metade da década de 1990, associados ao processo de descentralização. Eles necessitam se configurar em função dos recortes territoriais dos estados e estabelecer mecanismos formais de relacionamento com as instâncias de pactuação e gestão regional do SUS (LIMA, 2013), a exemplo das CIRs. Os consórcios enquanto modelos de parceria intergovernamental estão, nesse contexto, alinhados aos objetivos das CIRs. 
É oportuno salientar que as CIRs são instâncias deliberativas criadas em um contexto de "manutenção do protagonismo municipal e, concomitantemente, de fortalecimento das relaçóes de interdependência e corresponsabilidade sanitária entre os entes estadual e municipais" (SILVEIRA FILHO et al., 2016, p.855), com "a proposta de viabilizar, por meio de um planejamento regional, a integralidade das açôes e serviços nas regiōes de saúde” (SILVEIRA FILHO et al., 2016, p.855). Assim, é importante destacar que, desde a difusão dos consórcios intermunicipais, em meados dos anos 1990, Minas Gerais e Paraná foram os estados que obtiveram casos de maior sucesso (ROCHA, 2016).

A descentralização ocorrida na política de saúde do Brasil — sem a respectiva integração regional e com deficiências na oferta pública de serviços de maior complexidade, que geraram grandes vazios assistenciais - contribuiu para o crescimento do setor privado. Esse crescimento é financiado pelo Estado na forma de renúncias fiscais (MOREIRA; FERRÉ; ANDRADE, 2017; VIANA et al., 2015) e, como observado neste estudo, por meio da compra direta dos serviços de entidades privadas (ROMANO; SCATENA, 2014; SANTOS; UGÁ; PORTO, 2008).

Nesse contexto, é importante destacar que no Brasil existem desequilíbrios regionais importantes no acesso aos serviços de média e alta complexidade e na oferta de especialidades médicas (RIBEIRO et al., 2017; SILVA et al., 2017; SILVA et al., 2018). A fixação de profissionais de saúde em áreas remotas e rurais e nas periferias rurais-urbanas é um importante desafio enfrentado pelo sistema de saúde brasileiro (BRASIL, 2013; SILVA et al., 2018). Em Minas Gerais, diante da grande diversidade territorial, algumas regióes ampliadas de saúde, como o Jequitinhonha e as regiôes Oeste e Norte, apresentam menor desenvolvimento socioeconômico, menor capacidade de oferta de serviços e maior dificuldade de fixação de profissionais (MOREIRA; FERRÉ; ANDRADE, 2017).

A dificuldade de acesso a serviços de média complexidade em municípios de pequeno porte, incluindo as especialidades médicas, é observada em estudo nacional (SILVA et al., 2017). Nesse cenário é importante salientar a dificuldade que as populaçôes de áreas rurais brasileiras residentes nos pequenos municípios enfrentam no acesso aos serviços de média e alta complexidade. Superar esse problema é um dos grandes desafios do SUS (BRASIL, 2013).

Em relação às fragilidades do processo de regionalização em saúde (classe 1), foi ressaltado que o financiamento insuficiente do sistema de saúde em um cenário de 
disputas políticas e fragmentação de recursos prejudica a provisão da atenção nas regióes de saúde (REIS et al., 2017; SHIMIZU et al., 2017). Para avançar em um sistema de base regional, é imprescindível superar o crônico e grave subfinanciamento do setor de saúde (REIS et al., 2017).

Na contramão dessa necessidade, em dezembro de 2016 foi aprovada pelo Congresso Nacional a Emenda Constitucional 95/2016, que estabeleceu um teto para os gastos públicos no Brasil por um período de 20 anos. A partir de 2018 os gastos federais com saúde e educação passaram a ser atualizados apenas pela inflação do ano anterior com base na variação do Índice de Preços ao Consumidor Amplo (IPCA) (RIZZOTTO et al., 2016; VIEIRA et al., 2018). Esse problema ameaça não apenas a proposta de regionalização, mas a viabilização do SUS. Assim, é necessária uma ampla discussão sobre o orçamento da União, composição das despesas financeiras e dívida pública, o que extrapola os objetivos deste trabalho.

Em relação à priorização do critério político ao técnico na organização das redes de atenção à saúde, ponto destacado como gargalo para o processo regionalização, é válido salientar que a otimização dos recursos é uma lógica necessária ao sistema de saúde. Alguns procedimentos são raros e caros. Portanto, não é razoável que existam em todo e qualquer município ou mesmo região (DUARTE et al., 2015; SILVA, 2011). É relevante que as redes de atenção contribuam para a racionalização dos gastos e melhor aproveitamento da oferta assistencial disponível (SILVA, 2011).

Foram ressaltadas as dificuldades para o acesso à assistência na média e alta complexidade nas regiôes de saúde (classe 6). Estudo realizado no Estado de Minas Gerais (ALVES et al., 2017) descreveu que a população atingida pelo câncer de mama na regiấo norte do estado enfrenta problemas relacionados ao acesso aos serviços de saúde, como percorrer grandes distâncias com péssimas condiçôes de estradas para tratarem a doença. Ademais, é importante destacar que as barreiras geográficas afetam o acesso dos usuários aos serviços de saúde de forma diferenciada, com prejuízos maiores àqueles mais pobres. Se eles necessitam viajar para serem atendidos e náo retornam às suas residências no mesmo dia do atendimento, encontram dificuldades financeiras para se manter na cidade, principalmente devido aos custos com hospedagem e alimentação (ALVES et al., 2017).

Nesse contexto, é relevante destacar que o sistema de saúde brasileiro necessita de uma política voltada à atençáo especializada e hospitalar na perspectiva do 
fortalecimento regional, com mecanismos de planejamento e monitoramento adequados às necessidades regionais (ALMEIDA et al., 2018). Ademais, o subfinanciamento desse sistema, com respectiva restrição da retaguarda terapêutica, aliado a mecanismos pouco eficientes de planejamento e programaçáo em saúde, compromete a cobertura dos vazios assistências nas regiôes de saúde (ALMEIDA et al., 2018; SANTOS et al., 2016).

\section{Considerações finais}

A regionalização em saúde em Minas Gerais apresenta importantes potencialidades, como a contribuiçáo dos consórcios para o aumento da qualidade na oferta dos serviços; o relevante trabalho do suporte institucional realizado pelos apoiadores dos COSEMS MG no âmbito da CIR; a utilização de plataformas on-line para disseminação de informaçôes, articulação e resolução de problemas na CIR; o relevante apoio técnico e operacional disponibilizado pelas secretarias executivas da CIR na definição de pautas das reuniôes; o ganho com economia de escala e escopo na organização dos serviços. Ademais, o estudo destaca o município como eixo organizador da regionalização em Minas Gerais e chama a atenção para a participação de prestadores de serviços nas reuniōes de CIR.

Existem, no entanto, grandes desafios para os avanços no processo de regionalização: a) financiamento insuficiente do SUS em um cenário de disputas políticas e fragmentação de recursos prejudica a provisão da atenção; b) dificuldade de acesso a serviços de média e alta complexidade compromete seriamente a integralidade da assistência no SUS; c) participação do controle social é reduzida ou inexistente em algumas regiôes; d) fragilidade na execução do PDR; e) construção de unidades de saúde baseada em critérios políticos; e f) crescente influência e participação do setor privado/particular no SUS. Sáo grandes desafios para a regionalização.

Enfrentar essas dificuldades é de fundamental importância para a viabilização de avanços na regionalização em Minas Gerais. Futuros estudos de abrangência nacional, que possam comparar os resultados de diferentes estados, poderão ser relevantes para o mapeamento de potencialidades e fragilidades comuns e para os avanços do processo de regionalização no contexto brasileiro. ${ }^{1}$ 


\section{Referências}

ALBUQUERQUE, M. V. de et al. Perspectivas de região e redes na política de saúde brasileira. Saúde em Debate, v. 39, n. spe, p. 28-38, 2015.

ALMEIDA, P. Fç de et al. Coordenação do cuidado e Atenção Primária à Saúde no Sistema Único de Saúde. Saúde em Debate, v. 42, n. spe1, p. 244-260, 2018.

ALVES, M. O. et al. A regionalização da saúde e a assistência aos usuários com câncer de mama. Saúde e Sociedade, v. 26, n. 1, p. 141-154, 2017.

BRASIL. Decreto no 7.508, de 28 de junho de 2011. Regulamenta a Lei no 8.080, de 19 de setembro de 1990, para dispor sobre a organização do Sistema Único de Saúde, o planejamento da saúde, a assistência à saúde e a articulação interfederativa, e dá outras providências. Brasília, DF: Presidência da República, [2011]. Disponível em: http://www.planalto.gov.br/ccivil_03/_ Ato2011-2014/2011/Decreto/D7508.htm. Acesso em: 26 maio 2020.

. Política Nacional de Saúde Integral das Populaçóes do Campo e da Floresta. Brasília, DF: Ministério da Saúde. Departamento de Apoio à Gestão Participativa, 2013. 48 p. Disponível em: http://bvsms.saude.gov.br/bvs/publicacoes/politica_nacional_saude_populacoes_campo. pdf. Acesso em: 26 maio 2020.

BRETAS JUNIOR, N. et al. Planejamento regional compartilhado em Minas Gerais: avanços e desafios. Saúde em Debate, v. 39, n. 107, p. 962-971, 2015.

CAMARGO, B. V.; JUSTO, A. M. IRAMUTEQ: Um software gratuito para análise de dados textuais. Temas em Psicologia, v. 21, n. 2, p. 513-518, 2013.

DUARTE, L. S. et al. Regionalização da saúde no Brasil: uma perspectiva de análise. Saúde e Sociedade, v. 24, n. 2, p. 472-485, 2015.

INSTITUTO BRASILEIRO DE GEOGRAFIA E ESTATÍSTICA. Panorama IBGE, Brasil/ Minas Gerais. Disponível em: <https://cidades.ibge.gov.br/brasil/mg/panorama>. Acesso em: 31 maio 2018.

JUNQUEIRA, M. G.; MOTTA, P. S. Estratégias de apoio institucional do COSEMS-MG visando ao fortalecimento da gestão municipal no espaço de gestão regional do SUS. In: PERES, A. M. et al. (Org.). Apoiadores Regionais: uma experiência brasileira. Rio de Janeiro: CEPESCIMS/UERJ/COSEMS/RJ, OPAS, 2014. p. 125-154.

LIMA, L. D. de. A coordenação federativa do sistema público de saúde no Brasil. A saúde no Brasil em 2030: prospecção estratégica do sistema de saúde saúde brasileiro. Rio de Janeiro: [s.n.], 2013. p. 73-139.

LIMA, L. D. de.; QUEIROZ, L. F. N. de et al. Descentralização e regionalização: dinâmica e condicionantes da implantação do Pacto pela Saúde no Brasil. Ciência \& Saúde Coletiva, v. 17, n. 7, p. 1903-1914, 2012. 
LIMA, L. D. de.; VIANA, A. L. A. et al. Regionalização e acesso à saúde nos estados brasileiros: condicionantes históricos e político-institucionais. Ciência \& Saúde Coletiva, v. 17, n. 11, p. 2881-2892, 2012.

NEVES, L. A.; RIBEIRO, J. M. Consórcios de saúde: estudo de caso exitoso. Cadernos de Saúde Pública, v. 22, n. 10, p. 2207-2217, 2006.

MALACHIAS, I.; LELES, F. A. G.; PINTO, M. A. S. Plano Diretor de Regionalização da Saúde de Minas Gerais. Belo Horizonte: Secretaria de Estado de Saúde de Minas Gerais, 2010.

MOREIRA, L. M. de C.; FERRÉ, F.; ANDRADE, E. I. G. Financiamento, descentralização e regionalização: transferências federais e as redes de atenção em Minas Gerais, Brasil. Ciência \& Saúde Coletiva, v. 22, n. 4, p. 1245-1256, 2017.

REIS, A. A. C. dos et al. Reflexôes para a construção de uma regionalização viva. Ciência \& Saúde Coletiva, v. 22, n. 4, p. 1045-1054, 2017.

RIBEIRO, J. M. et al. Políticas de saúde e lacunas federativas no Brasil: uma análise da capacidade regional de provisão de serviços. Ciência \& Saúde Coletiva, v. 22, n. 4, p. 1031$1044,2017$.

RIZZOTTO, M. L. F. et al. A esperança não morre quando sonhamos juntos. Saúde em Debate, v. 40, n. 111, p. 5-8, 2016.

ROCHA, C. V. A cooperação federativa e a política de saúde: o caso dos Consórcios Intermunicipais de Saúde no estado do Paraná. Cadernos Metrópole, v. 18, n. 36, p. 377-399, 2016. ROMANO, Cátia Maria Costa; SCATENA, João Henrique Gurtler. A relação público-privada no SUS: um olhar sobre a assistência ambulatorial de média e alta complexidade na região de saúde da Baixada Cuiabana em Mato Grosso. Revista de Administração Pública, v. 48, n. 2, p. 439-458, 2014.

SANTOS, A. M. dos et al. Gestão do cuidado integral: estudo de caso em região de saúde da Bahia, Brasil. Cadernos de Saúde Pública, v. 32, n. 3, 2016.

SANTOS, I. S.; UGÁ, M. A. D.; PORTO, S. M. O mix público-privado no Sistema de Saúde Brasileiro: financiamento, oferta e utilização de serviços de saúde. Ciência \& Saúde Coletiva, p. 1431-1440, 2008.

SHIMIZU, H. E. et al. O protagonismo dos Conselhos de Secretários Municipais no processo de governança regional. Ciência \& Saúde Coletiva, p. 1131-1140, 2017.

SILVA, C. R. et al. Dificuldade de acesso a serviços de média complexidade em municípios de pequeno porte: um estudo de caso. Ciência \& Saúde Coletiva, v. 22, n. 4, p. 1109-1120, 2017.

SILVA, S. F. da. Organização de redes regionalizadas e integradas de atenção à saúde: desafios do Sistema Único de Saúde (Brasil). Ciência \& Saúde Coletiva, v. 16, n. 6, p. 2753-2762, 2011. 
SILVA, E. et al. Cost of providing doctors in remote and vulnerable areas: Programa Mais Médicos in Brazil. Revista Panamericana de Salud Pública, v. 42, p. 1-7, 2018.

SILVA, E. C.; GOMES, M. H. de A. Impasses no processo de regionalização do SUS: tramas locais. Saúde e Sociedade, v. 22, n. 4, p. 48-59, 2013.

SILVEIRA FILHO, R. M. et al. Açôes da Comissão Intergestores Regional para gestão compartilhada de serviços especializados no Sistema Único de Saúde. Physis: Revista de Saúde Coletiva, v. 26, n. 3, p. 853-878, 2016.

VIANA, A. L. A. et al. Tipologia das regiôes de saúde: condicionantes estruturais para a regionalização no Brazil. Saude e Sociedade, v. 24, n. 2, p. 413-422, 2015.

VIEIRA, F. S. et al. Politicas Sociais e Austeridade Fiscal: como as políticas sociais são afetadas pelo austericídio da agenda neoliberal no Brasil e no mundo. Rio de Janeiro: CEBES, 2018.

\section{Nota}

${ }^{1}$ V.O. de M. Pereira participou da organização e análise dos dados, redação do artigo, discussão dos resultados e aprovou a versão final. H. E. Shimizu, M. C. Ramos e C. W. participaram da discussáo dos resultados, revisão e aprovação da versão final do artigo. 


\section{Abstract}

\section{Health Regionalization in Minas Gerais: An Analysis of the Perception of Representatives of Regional Inter-managerial Commissions} This study aims to analyze the perception of representatives of Regional Inter-managerial Commissions on the process of health regionalization in the State of Minas Gerais. Interviews were conducted with representatives of 10 state health regions. The data, analyzed through IRAMUTEQ software, generated a dendogram with two thematic axes. The first axis, called "The role of CIR and key actors in the regional governance process", was subdivided into classes 4, 3 and 2, which addressed, respectively, the role of the Council of Municipal Health Secretaries supporters in the Commissions; the Commissions as a space for agreement on regional actions; the actors involved in the governance of the health region. The second, called "Organization of assistance in the care networks" was subdivided into classes 5, 1 and 6, which described, respectively, care gaps in the health regions; weaknesses and potentialities of the regionalization process; difficulties in providing medium and high complexity services. Health regionalization in Minas Gerais, despite successful strategies, brings great challenges. Insufficient financing of the SUS in a scenario of political disputes and resource fragmentation undermines the provision of care in health regions. It is a process still under construction.

> Keywords: Regional Health Planning; Unified Health System; governance; decentralization; health services. 